\title{
Delimitação do usuário nas etapas de criação, modelagem e prototipagem do produto de vestuário
}

Elen Makara

Lizandra Garcia Lupi Vergara 


\section{Delimitação do usuário nas etapas de criação, modelagem e prototipagem do produto de vestuário \\ Elen Makara, Giselle Schmidt Alvez Díaz Marino e Lizandra Garcia Lupi Vergara}

\section{Resumo}

Em virtude das reclamações de roupas que não vestem bem e incomodam, ou mesmo da dificuldade de adquirir uma roupa adequada para uma ocasião, a indústria de confecção de vestuário pode estar deixando de considerar o usuário no desenvolvimento de seus produtos. O objetivo deste artigo foi verificar se nas etapas de criação, modelagem e prototipagem de produtos do vestuário o usuário está sendo considerado, visto que para um projeto de design o correto é considerá-lo em todas as etapas do desenvolvimento. Para isto foi realizada uma pesquisa bibliográfica e entrevistas com profissionais da área. Com os resultados obtidos foi possível perceber a dificuldade que os profissionais possuem em definir o público para a criação das peças. Também verificou-se que a maioria dos profissionais compreende a importância da tabela de medidas porém acabam ajustando-a de forma empírica, e para a realização dos testes de prototipagem, muitos escolhem modelos que não condizem com a realidade do público da empresa.

Palavras- chave: design de moda; desenvolvimento de vestuário; usuário.

\begin{abstract}
Because of complaints of clothes that do not fit well and bother, or even the difficulty of acquiring a suitable outfit for an occasion, to the clothing industry may be failing to consider the user in developing their products. The aim of this paper was to determine whether the steps for creating, modeling and prototyping of garment products the user is being considered, as for a design project is right to consider it at all stages of development. For this a literature review and interviews with professionals was held. With the results we can see the difficulty that professionals have to define the public to create the pieces. We also found that most professionals understand the importance of measures table however end up adjusting the empirically, and the realization of prototype testing many choose models that does not match the reality of the public company.
\end{abstract}

Keywords: fashion design; development of clothing; user 


\section{Introdução}

Inúmeros são os relatos de peças do vestuário que apertam e ocasionam os mais variados incômodos, como as que dificultam a respiração, comprometem a circulação sanguínea ou prejudicam a movimentação dos membros inferiores $\mathrm{e}$ superiores. Rosa (2011) afirma que o vestuário deve permitir a interação entre usuário, produto e ambiente, e sem esta correta adequação além do desconforto o vestuário pode vir a ocasionar acidentes e danos à saúde.

$\mathrm{Na}$ etapa de criação ou concepção dessas peças, o profissional designer de moda pode estar com dificuldades em visualizar seu público-alvo. Essas peças também podem apresentar falhas relacionadas ao seu desenvolvimento no setor de modelagem, o qual pode estar desconsiderando a forma do corpo e medidas do seu consumidor. Já o setor de prototipagem também pode estar negligenciando a importância dos testes dos protótipos junto a modelos ou manequins com medidas correspondentes ao público-alvo da empresa.

Este artigo pretendeu verificar através de entrevistas realizadas com profissionais da área, se nas etapas de criação, modelagem e prototipagem de produtos do vestuário o usuário está sendo considerado, visto que para um projeto de design o correto é considerá-lo em todas as etapas do processo de desenvolvimento do produto. Também foi realizada uma pesquisa bibliográfica em livros, artigos, teses e dissertações com o propósito de explicar as etapas do processo de desenvolvimento de produto do vestuário e comparar com as respostas dadas nas entrevistas.

Em virtude das reclamações de roupas que não vestem bem e incomodam, ou mesmo da dificuldade de adquirir uma roupa adequada para uma ocasião, a indústria de confecção de vestuário pode estar deixando de considerar o usuário no desenvolvimento de seus produtos. Diante disso, o presente estudo justifica-se pela importância de considerar o usuário em todas as etapas do processo de desenvolvimento de produto do vestuário, para aprimorar o conforto e a satisfação de usuários durante o uso de vestuário. 


\section{Processo de desenvolvimento de produto do vestuário}

Para Montemezzo (2003, p.45), é fundamental que o processo de desenvolvimento do vestuário esteja focado no usuário/consumidor. A autora afirma que existe uma relação estreita e pessoal desses produtos com seu usuário e diante disso é necessário que estes proporcionem conforto, facilidade de manuseio e uso, prazer estético, confiabilidade e apresentem coerência entre valores agregados e preço.

Sanches (2014, p. 298) afirma que é necessário ter "consciência efetiva sobre o perfil do usuário do produto em desenvolvimento, pois é este universo que fornecera as diretrizes para o direcionamento e formulação do conceito projetual.”.

Para esclarecer o processo de desenvolvimento de produto do vestuário, elaborou-se uma tabela com bases nos autores: Treptow (2013), Sanches (2014), Sorger e Udale (2009), Rech (2002), Renfrew e Renfrew (2010) e Montemezzo (2003). Após análise, é possível perceber que a primeira etapa em todos os processos se inicia com o planejamento, pesquisa ou coleta de informações. Na Tabela 01, seguem explicações gerais sobre as etapas dos processos de desenvolvimento de produto do vestuário.

Tabela 01: Processo de desenvolvimento do produto de moda

\begin{tabular}{|c|c|c|c|c|c|}
\hline $\begin{array}{l}\text { Autores/ } \\
\text { Etapas }\end{array}$ & \multicolumn{2}{|c|}{ Criação } & \multicolumn{3}{|c|}{$\begin{array}{l}\text { Modelagem e } \\
\text { Prototipagem }\end{array}$} \\
\hline $\begin{array}{l}\text { Treptow } \\
(2013)\end{array}$ & Planejamento & Design & Desenvolvimento & Produção & $\begin{array}{l}\text { Comercializa } \\
\text { ção }\end{array}$ \\
\hline $\begin{array}{l}\text { Sanches } \\
(2014)\end{array}$ & Planejamento & $\begin{array}{l}\text { Conceito } \\
\text { Gerador }\end{array}$ & $\begin{array}{l}\text { Geração de } \\
\text { altemativas }\end{array}$ & $\begin{array}{l}\text { Avaliação e } \\
\text { detalhament } \\
0\end{array}$ & Produção \\
\hline $\begin{array}{l}\text { Sorger e } \\
\text { Udale } \\
(2009)\end{array}$ & Pesquisa & Modelo & Modelagem & Protótipo & $\begin{array}{c}\text { Lançamento } \\
\text { da coleção }\end{array}$ \\
\hline $\operatorname{Rech}(2002)$ & $\begin{array}{c}\text { Coleta de } \\
\text { Informações }\end{array}$ & $\begin{array}{l}\text { Definição } \\
\text { de Tema }\end{array}$ & $\begin{array}{l}\text { Esboço de } \\
\text { Modelos }\end{array}$ & $\begin{array}{c}\text { Definição de } \\
\text { Modelo }\end{array}$ & \\
\hline $\begin{array}{c}\text { Renfrew e } \\
\text { Renfrew } \\
(2010)\end{array}$ & Pesquisa & Criação & Desenvolvimento & Edição & Apresentação \\
\hline $\begin{array}{c}\text { Montemezzo } \\
(2003)\end{array}$ & Planejamento & $\begin{array}{l}\text { Especifica } \\
\text { ção do } \\
\text { projeto }\end{array}$ & $\begin{array}{l}\text { Delimitação } \\
\text { conceitual } \\
\text { e Geração de } \\
\text { Alternativas }\end{array}$ & $\begin{array}{l}\text { Avaliação e } \\
\text { elaboração }\end{array}$ & Produção \\
\hline
\end{tabular}

Fonte: Elaborado pelas autoras, 2016. 
Renfrew e Renfrew (2010) afirmam que para desenvolver uma coleção é indispensável pesquisa, investigação, planejamento, conhecimento das necessidades dos clientes e do posicionamento da empresa no mercado. Para Rech (2002) após a coleta de informações, ou seja, a pesquisa, é feita a definição do tema da coleção que além de refletir as tendências, deve estar de acordo com a filosofia da empresa e satisfazer as necessidades do consumidor.

De acordo com Treptow (2013), é necessário realizar uma reunião de planejamento na qual se discuta o cronograma e a dimensão da coleção. O cronograma organiza as atividades previstas atribuindo datas de execução, e geralmente essas datas são estipuladas para que o lançamento da coleção esteja disponível no mercado no momento certo, seguindo calendário nacional têxtil. Matharu (2011) explica que o calendário da moda é baseado nas mudanças anuais de estação, e exige organização e estrutura de todo o mercado, fornecedores, fabricantes e varejo para acompanhar os prazos de entrega.

Matharu (2011) ressalta a importância da pesquisa, de novas fontes de inspiração e estímulo visual para o surgimento de novos designs. Explica que existem duas vertentes de pesquisa em design de moda, sendo a primeira a de reunir objetos reais e tangíveis (tecidos, aviamentos, e outros objetos) e a segunda de um método mais abstrato, visual e investigativo através de livros, revistas, periódicos e internet,

Para Renfrew e Renfrew (2010), a partir da pesquisa, é possível extrair um tema para a coleção, o qual os designers de moda ao desenvolver a coleção junto à equipe, explicam-no utilizando imagens, desenhos, painéis de inspiração, roupas, cartela de cores, tecidos e aviamentos encontrados durante a pesquisa.

Depois do tema escolhido, cartela de cores, de tecidos e de aviamentos o profissional responsável pela criação, o estilista ou designer de moda, passa a criar propostas para a coleção. Na etapa de criação, os desenhos de moda podem ser realizados à mão ou assistido por computador, este último torna o processo mais ágil e preciso e podem ser realizados em programas de desenho vetorial tais como o Corel Draw, Illustrator, Inkcape, entre outros.

Rosa (2011) explica que o estilista pode construir painéis, com base nas pesquisas realizadas, para auxiliá-lo na criação de novas peças do vestuário. Alguns exemplos desses painéis são o de tendências de moda, de tema, do briefing e do 
consumidor. Este último tem objetivo de traduzir as características e costumes do consumidor, uma vez que essas imagens representam seu comportamento. O ideal é realizar uma leitura diária desses painéis, pois assim será possível captar o estilo do produto, no que se refere a custos e outros valores que serão determinantes no momento da aquisição de um artigo do vestuário e que esteja de acordo com o estilo de vida do consumidor.

Portanto, o designer de moda além de estar atento às novidades e tendências da moda e a realidade da empresa, ele também deve conhecer profundamente seu mercado-alvo (TREPTOW, 2013). De acordo com a autora, a identificação do mercado e o desenvolvimento de produtos para um público alvo pré-definido faz parte do processo de planejamento e desenvolvimento de uma coleção. Rosa (2011, p.43) corrobora com a autora, ao afirmar que o "criador gera produtos unindo tendências sazonais de moda e as informações sobre o público-alvo, sem se distanciar das estratégias da empresa, no que se refere à base de dados, principalmente, dos setores de marketing, vendas, compras, custos e produção".

Antes de passar os modelos para o setor de modelagem, é necessário avaliar a proposta da coleção em uma reunião de definição, onde se analisam os custos e a viabilidade de produção, e a capacidade de absorção do produto no mercado. Apenas para os modelos que foram aprovados devem ser feitos os desenhos técnicos, os quais possuem o máximo de detalhes e informações que sejam úteis para o setor de modelagem (TREPTOW, 2013).

As fichas com os desenhos técnicos dos modelos aprovados na reunião de definição seguem para a etapa da modelagem que compõem o processo de desenvolvimento do vestuário através da criação dos moldes, nos quais se reproduzem planificadamente as formas e medidas do corpo humano, de acordo com a tabela de medidas do público-alvo da empresa. A pessoa responsável pela elaboração dos moldes é o modelista, e Rosa (2011) explica que é este profissional que analisa o desenho vindo do setor de estilo, escolhe a técnica de modelagem apropriada para conferir à roupa as formas e detalhes que foram desenvolvidos na fase de criação. Também deve utilizar uma tabela de medidas adequadas ao público da empresa que permita confeccionar os protótipos. 
Para Silveira (2011), o vestuário possui uma interação generalizada e direta com o corpo humano, como uma segunda pele, e por este motivo, é importante que as roupas proporcionem conforto, funcionalidade, qualidade de vida e que satisfaçam as necessidades do usuário. Para a autora, o desenvolvimento da modelagem vai além da escolha correta de uma das técnicas mencionadas, sendo necessário obsevar e compreender as formas e funcionamento do corpo humano.

Após a interpretação do modelo, com os moldes já finalizados e com as devidas informações, é preciso testá-los com a confecção de um protótipo a fím de visualizar o caimento da peça, o encaixe dos moldes, a proporção dos recortes. Nesta fase, a montagem é realizada pela costureira pilotista, que é especialista em preparar, costurar e acabar a peça piloto, tendo em vista que a peça a ser confeccionada requer atenção e cuidados, pois a partir dela, as criações deixam de ser somente conceito e se transformam em produto (ROSA, 2011).

Depois da confecção do protótipo, realiza-se uma prova e ajustes em uma pessoa selecionada por suas medidas condizerem com as bases das modelagens e o público-alvo da empresa. Para Renfrew e Renfrew (2010), é fundamental a contratação de um modelo de prova, cujas medidas e altura estejam de acordo com o público da empresa, para refinar e confirmar as proporções exatas, posicionamento de detalhes, movimento e aparência geral.

Por fim, realizada a prova e os ajustes necessários o protótipo aprovado passará para a etapa da produção em série. Caso o protótipo seja reprovado, após a avaliação de ajuste, ele será arquivado ou descartado, e se houverem alterações é necessário que volte para o setor de modelagem para que as correções sejam feitas e um novo protótipo seja confeccionado.

\section{Procedimentos metodológicos}

Este artigo se caracteriza como uma pesquisa qualitativa, e quanto à natureza do seu objetivo é uma pesquisa exploratória. Entre os procedimentos metodológicos empregados foi realizada uma pesquisa bibliográfica em livros, teses e dissertações, a respeito das etapas de desenvolvimento de produto de vestuário. Também foram realizadas entrevistas semiestruturadas com 15 profissionais da área, os quais estão atuando como estilistas, modelistas ou auxiliares. O Quadro 01 apresenta o 
roteiro da entrevista composto pela identificação pessoal, formação acadêmica, atuação profissional e perguntas.

Quadro 01: Roteiro das entrevistas semiestruturadas realizadas com profissionais da área de desenvolvimento de produto do vestuário

\section{Roteiro para entrevistas}

1) Nome:

2) Sexo: feminino ( ) masculino ( )

3) Idade:

4) Grau de Instrução:

( ) Técnico ( ) Graduação ( ) Pós-graduação

5) Qual a função que você exerce no processo de desenvolvimento de produto do vestuárioe a quanto tempo está desempenhando esta função?

6) Em sua trajetória profissional, como você descreve as etapas do desenvolvimento deproduto do vestuário?

7) Vocêjá teve acesso a alguma material sobre definição imagem de público-alvo ou realizou algum tipo de pesquisa sobre as necessidades e exigências do consumidor?

8) Como você visualiza o processo de desenvolvimento de produto do vestuário dentro do setor de modelagem?

9) Você já presenciou a confecção de protótipos/peças piloto e acompanhou a realização de testes antes de aprovar para produção em série?

10) Você sabe como foi definida a tabela de medidas?

Fonte: Elaborado pelas autoras, 2016.

A pesquisa foi aprovada pelo Comitê de Ética em Pesquisas com Seres Humanos da Universidade Estadual de Santa Catarina, parecer número 1.691.941. Os participantes foram selecionados por conveniência e convidados a realizar a entrevista na qual assinaram o Termo de Consentimento Livre e Esclarecido, concordando em participar da amostra como voluntários, de forma confidencial e anônima.

Todas as entrevistas foram gravadas e transcritas. Utilizou-se a técnica de análise de conteúdo que resultou na elaboração de três categorias: etapa de criação de produto do vestuário com definição público-alvo; etapa modelagem com informações das medidas antropométricas do público-alvo; etapa de confecção do protótipo e realização de testes.

Para auxiliar a análise de conteúdo, foi utilizada a proposta de tratamento de material de Guerra (2012), a qual é orientada para um número entre 15 a 20 
entrevistados, como é o caso desta pesquisa, e que consiste nas transcrições e leitura das entrevistas, construção das sinopses, análise descritiva e interpretativa.

\section{Resultados}

\subsection{Caracterização da amostra}

A pesquisa contou com a participação de 15 profissionais da área de desenvolvimento de produto de vestuário, sendo 6 estilistas, 3 modelistas, 2 com funções acumuladas de estilista e modelista, 4 auxiliares de modelagem. A amostra teve 11 mulheres e 4 homens com idade entre 21 e 51 anos. O tempo de atuação na área varia de 5 meses a 14 anos. A respeito do grau de instrução dos entrevistados, 5 possuem curso técnico em modelagem do vestuário, 4 graduação em design de moda e 2 estão cursando, 4 possuem pós-graduação.

A Tabela 02 apresenta a função de cada entrevistado identificando o tipo de produto que desenvolve, para qual idade e gênero do público-alvo. Observa-se que 9 profissionais desenvolvem produtos para marcas próprias, 4 apenas para magazines e 2 para ambos. Em relação à faixa etária do público-alvo, 6 trabalham com infantil/juvenil, 6 com público adulto, e 3 com ambos. Apenas 2 profissionais trabalham somente com público masculino, 4 para público feminino e 9 com ambos os públicos. 
Tabela 02: Caracterização da amostra

\begin{tabular}{|c|c|c|c|c|}
\hline \multirow{2}{*}{ Entrevistado } & \multirow{2}{*}{ Função } & \multicolumn{3}{|c|}{ Segmentação } \\
\hline & & Produto & Faixa Etária & Sexo \\
\hline E1 & Modelista & Marca Própria - malha & Infantil/Juvenil & $\begin{array}{l}\text { Feminino } \\
\text { Masculino }\end{array}$ \\
\hline E2 & $\begin{array}{c}\text { Auxiliar } \\
\text { Modelagem }\end{array}$ & $\begin{array}{c}\text { Marca Própria } \\
\text { malha e tecido plano }\end{array}$ & Adulto & $\begin{array}{l}\text { Feminino } \\
\text { Masculino }\end{array}$ \\
\hline E3 & Modelista & Marca Própria - malha & Infantil/Juvenil & $\begin{array}{l}\text { Feminino } \\
\text { Masculino }\end{array}$ \\
\hline E4 & $\begin{array}{c}\text { Auxiliar } \\
\text { Modelagem }\end{array}$ & Magazine-malha & $\begin{array}{c}\text { Adulto } \\
\text { Infantil/Juvenil }\end{array}$ & $\begin{array}{l}\text { Feminino } \\
\text { Masculino }\end{array}$ \\
\hline E5 & Modelista & Marca própria-Jeans & Adulto & $\begin{array}{l}\text { Feminino } \\
\text { Masculino }\end{array}$ \\
\hline E6 & $\begin{array}{c}\text { Auxiliar } \\
\text { Modelagem }\end{array}$ & Marca Própria - Pijama & $\begin{array}{c}\text { Adulto } \\
\text { Infantil/Juvenil }\end{array}$ & $\begin{array}{l}\text { Feminino } \\
\text { Masculino }\end{array}$ \\
\hline E7 & Estilista & Magazine-malha & Infantil/Juvenil & Masculino \\
\hline E8 & $\begin{array}{c}\text { Auxiliar } \\
\text { Modelagem }\end{array}$ & Marca Própria - malha & Infantil/Juvenil & $\begin{array}{l}\text { Feminino } \\
\text { Masculino }\end{array}$ \\
\hline E9 & $\begin{array}{l}\text { Estilista e } \\
\text { Modelista }\end{array}$ & $\begin{array}{l}\text { Magazine e Marca Própria } \\
\text { Malha e tecido plano }\end{array}$ & Adulto & Feminino \\
\hline E10 & Estilista & Marca Própria - malha & Infantil/Juvenil & Masculino \\
\hline E11 & $\begin{array}{l}\text { Estilista e } \\
\text { Modelista }\end{array}$ & Marca Própria - malha & Adulto & Feminino \\
\hline E12 & Estilista & $\begin{array}{l}\text { Magazine e Marca Própria } \\
\text { - Malha }\end{array}$ & $\begin{array}{c}\text { Adulto } \\
\text { Infantil/Juvenil }\end{array}$ & $\begin{array}{l}\text { Feminino } \\
\text { Masculino }\end{array}$ \\
\hline E13 & Estilista & $\begin{array}{c}\text { Magazine - } \\
\text { Jeans }\end{array}$ & Infantil/Juvenil & $\begin{array}{l}\text { Feminino } \\
\text { Masculino }\end{array}$ \\
\hline E14 & Estilista & Marca Própria - malha & Adulto & Feminino \\
\hline E15 & Estilista & $\begin{array}{l}\text { Magazine - } \\
\text { Jeans }\end{array}$ & Adulto & Feminino \\
\hline
\end{tabular}

Fonte: Elaborado pelas autoras, 2016.

\subsection{Visualização do processo de desenvolvimento de produto do vestuário dos entrevistados}

Os entrevistados relataram por quais etapas passa o desenvolvimento de produto do vestuário e entre as mais lembradas destaca-se a pesquisa de moda, o desenvolvimento/desenho do setor de estilo, a modelagem e a prototipagem conforme Tabela 03. 
Tabela 03: Etapas de desenvolvimento de produto do vestuário

\begin{tabular}{|c|c|}
\hline Etapas & Frequência \\
\hline Pesquisas & 14 \\
\hline Desenvolvimento/Desenho & 13 \\
\hline Modelagem & 15 \\
\hline Prototipagem & 15 \\
\hline Briefing & 3 \\
\hline Fornecedores Materiais & 2 \\
\hline Encaixe & 2 \\
\hline Corte & 3 \\
\hline Estamparia/Aplique/Lavanderia & 6 \\
\hline Costura & 7 \\
\hline Revisão & 2 \\
\hline Embalagem & 1 \\
\hline Graduação & 1 \\
\hline
\end{tabular}

Fonte: Elaborado pelas autoras, 2016.

Sobre as fontes de pesquisas, 8 realizam pesquisas na internet em sites gratuitos, 1 destacou o uso de sites pagos (Use Fashion), 2 realizam pesquisas em shoppings e lojas, 1 viaja para feiras nacionais e apenas 1 viaja para pesquisas no exterior. Três entrevistados afirmaram que não fazem pesquisa, pois as recebem prontas dos clientes e trabalham em cima dessas informações para desenvolver os produtos. Os entrevistados E2, E9 e E14 apresentam desconforto ao falar sobre a realização das pesquisas: “... é feita na internet, bem rala...”, “... a gente não tem site, a empresa não paga...”, “...em sites não pagos... a empresa não investe muito em pesquisa...”.

A respeito do modelo da peça desenhado pelo estilista, 7 entrevistados apontaram o uso de computador, 1 entrevistado comentou que realiza os croquis à mão, 1 entrevistado afirmou que os modelos vêm de imagens e fotos de peças de outras empresas , 1 entrevistado falou que se utiliza de imagens prontas e que também realiza desenho no computador ou à mão e o restante não informou como eram desenvolvidos os croquis.

Para auxiliar na criação dos modelos, 3 entrevistados comentaram o desenvolvimento de painéis, os quais contam com imagens, modelos, tendências, amostras de tecidos, aviamentos, e tudo o que possa vir inspirar dentro do tema da coleção a ser desenvolvida.

Todos os entrevistados destacaram o uso de computador, ou de sistemas específicos para o desenvolvimento da modelagem das peças de vestuário dentro do 
setor de modelagem. Houve a ocorrência de um entrevistado que mencionou o desenvolvimento de peças da coleção feminina através da modelagem tridimensional, realizada sobre o manequim e depois passada para o computador com o auxílio da mesa digitalizadora.

\subsection{Obtenção e utilização das informações sobre o público-alvo para a etapa de criação do produto de vestuário}

Treptow (2013) explica que o público-alvo pode ser divido de acordo com aspectos demográficos, psicográfico, comportamentais ou geográficos. A segmentação demográfica se refere à idade, rendimento, sexo, tipo físico; já o psicográfico considera estilo de vida, classe social e a personalidade; a segmentação geográfica remete ao local em que o consumidor mora, o clima predominante e as estações climáticas. Para desenvolver um produto adequado ao público-alvo devem-se levar em consideração esses critérios.

Para obter informações sobre o hábito de consumo do seu público-alvo, Sorger e Udale (2009) sugerem conversar com os profissionais de merchandising ou compradores para conhecer quais as roupas que venderam bem ou não de coleções anteriores ou atuais.

Algum tempo atrás, as pesquisas de público-alvo eram baseadas em informações básicas como: sexo, idade, e classe socioeconômica. Porém, nos dias de hoje, é necessário compreender o estilo de vida do público-alvo, pois "pessoas de diferentes idades podem ter os mesmos gostos, a mesma maneira de pensar e mesmos interesses. Assim, selecionar o público apenas pela idade não é mais recomendável" (VICENTINI, 2010, p.81).

Ao serem questionados sobre a definição do perfil do público-alvo para o qual desenvolve os produtos de vestuário, os entrevistados responderam de acordo com diferentes critérios. Conforme Tabela 04 abaixo, 4 entrevistados definiram seu público de acordo com faixa-etária, 2 afirmaram que essa informação vem da análise do histórico de vendas, 6 através da troca de informações com os representantes, 1 pelo estilo do produto, 2 de acordo com o conforto do produto, 4 definiram seu público através do custo final do produto, 2 através do uso de informações das tendências de moda, 4 pela classe social e 1 pelas características físicas do consumidor. Os 
entrevistados E2, E9 e E14 apresentam uma definição abrangente em relação ao público-alvo: “... é uma coisa meio assim: de 8 a 80 , faz para todo mundo...”; “... a gente faz um pouco de cada coisa na coleção, um pouco mais senhora, outro pouco mais moderninho...”; “... queria atingir vários públicos, de uma faixa etária de 18 a 50 anos...”.

Tabela 04: Obtenção de informações do público-alvo

\begin{tabular}{|c|c|}
\hline Formas de definição & Frequência \\
\hline Definição abrangente & 3 \\
\hline Faixa etária & 4 \\
\hline Histórico de Vendas & 2 \\
\hline Representantes & 5 \\
\hline Tipo de produto & 1 \\
\hline Conforto do produto & 2 \\
\hline Custo do produto & 4 \\
\hline Tendências de moda & 2 \\
\hline Classe social & 4 \\
\hline Características físicas & 1 \\
\hline Região do país & 1 \\
\hline Tamanho produto & 1 \\
\hline
\end{tabular}

Fonte: Elaborado pelas autoras, 2016.

O entrevistado E3 foi quem definiu seu público-alvo envolvendo quatro critérios de definição expostos no quadro acima, sendo pela faixa-etária, representantes, conforto do produto e classe social. De acordo com E3, o produto final é para bebês e crianças de 1 a 12 anos; não é povão; existe a preocupação se algo que possa incomodar, espetar ou esquentar demais, e que os próprios representantes passam muita informações a respeito do que está ou não vendendo. Na sequência, o entrevistado E10 utiliza três critérios de definição: faixa-etária, custo do produto e tendências de moda. $\mathrm{O}$ público-alvo de E10 é "1 a 8 ou de 4 a 14 anos... precisa cuidar muito com o custo final do produto... as crianças e os pais gostam de estampas mais moderninhas, sem tanto "frufruzinho", pois estão vestindo crianças como adultos". Os demais entrevistados utilizaram apenas 1 ou 2 critérios para definir seu público-alvo.

Destacando a importância de conhecer o público-alvo para criar novos produtos que atendam as necessidades e desejos do consumidor, apenas o entrevistado E5 considerou isso ao explicar as etapas do processo de desenvolvimento de produto do vestuário no qual trabalha: "a partir da pesquisa das tendências e do público-alvo que a estilista desenha os modelos...". 
O entrevistado E14 comenta sobre a dificuldade de criar de forma a atender vários públicos-alvo: “eu tinha que imaginar vários públicos, ou então criar uma peça coringa, que servisse tanto para o público de 20 anos quanto o de 50... tem essa dificuldade em não ter o público bem definido”.

Sobre a obtenção de informações a respeito das necessidades e exigências do consumidor, os participantes E5 e E11 afirmaram que realizam questionários com seus principais clientes fornecedores, através do auxílio dos seus representantes: " $a$ gente não tem acesso direto aos nossos clientes então acaba fazendo esse serviço através dos nossos representantes... eles acabam fazendo uns questionários sobre nossos produtos sobre os tecidos utilizados, se veste bem, se a peça além de bonita dá um caimento legal...", "os clientes mais ativos, respondem um questionário, com algumas perguntas sobre nosso produto... se tem boa saída na loja deles, se eles encontraram algum problema no produto ou na modelagem, se as cores estão corretas e se a entrega foi realizada dentro do prazo". A entrevistada E12 afirma que nenhuma pesquisa foi feita, pois eles trabalham em cima do que os magazines solicitam.

\subsection{Conhecimento sobre a tabela de medida e sua relação com público-alvo- Reconhecimento do usuário da etapa de modelagem}

Boueri (2010) comenta sobre uma instituição de ensino e pesquisa que elaborou para uma indústria de meias um estudo de medidas do corpo da brasileira conforme procedimentos recomendados para uma pesquisa antropométrica. A partir da nova tabela proposta, com medidas maiores e menores em peso e estatura, a indústria conseguiu maior adequação do seu produto ao perfil antropométrico das usuárias e aumentou a satisfação dos consumidores. Diante deste caso, Boueri (2010, p. 354) afirma que "a indústria têxtil e da moda pode estar trabalhando com informações não reais do mercado consumidor, prejudicando, assim, a qualidade dos seus produtos”.

Oito entrevistados afirmaram não ter conhecimento sobre a concepção da tabela de medidas utilizada pela empresa onde trabalham, de acordo com as expressões: "não sei como foi feita a tabela de medidas, quando entrei já existia”, "não sei por que é uma coisa muito antiga”, "provavelmente quando a empresa foi fundada já veio com uma medida", "existe a muito tempo e foi aprovada pela empresa", "não sei 
exatamente como ela foi definida, na verdade não trabalhava lá e também não me falaram", "não acompanhei a fase de implementação da tabela".

Dois entrevistados explicam que utilizam as medidas de tabelas que são disponibilizadas pelos seus clientes como os magazines, e que por esse motivo não têm conhecimento de como foram construídas.

Três entrevistados explicam que a tabela foi desenvolvida com o passar dos anos. Para E11, que exerce as funções de modelista e estilista e é um dos proprietários da empresa, explica que "a tabela foi construída e depois ajustada de acordo com alguns padrões que a gente achou interessante, que seria comprimento de manga, perímetro do busto... foi trabalhando dentro do padrão de necessidade de clientes de cada região que a gente foi recebendo pedidos". Ainda de acordo com E11, existe uma preocupação em relação à precisão dos tamanhos das peças: "quem comprar uma peça $P$ vai sempre comprar uma peça $P$ da minha marca".

O entrevistado E11 comentou a respeito da diferença de tamanhos que constam nos pedidos enviados para a região nordeste ou extremo sul do Brasil. Segundo E11 o nordeste não compra tamanho GG, apenas $P, M$ e G, já o Rio Grande do Sul elimina um pouco da quantidade do tamanho P, e compra mais M, G e GG. A distinção dos pedidos também se verifica nas cores, pois o nordeste evita o preto e no sul a restrição é com o amarelo e laranja.

O entrevistado E6 comenta que devido a problemas com a modelagem das peças infantis a empresa em que trabalha realizou uma pesquisa na ABNT, e em peças de outras empresas que também trabalham com o mesmo público e construíram uma média. Após a pesquisa, confeccionaram as peças e provaram em crianças. De acordo com E6, a empresa recebia muitas reclamações: “... minha filha tem oito anos e usa o doze daqui...", ou do próprio representante que não estava vendendo as peças. Depois de analisar os fatos, a empresa revolveu fazer algo para melhorar as peças e atender de melhor forma o consumidor.

Para o entrevistado E14, a tabela de medidas foi retirada de um site especializado em modelagem. Para E13, a tabela de medidas foi montada em cima de modelos que serviam bem, e a partir disso as graduações para os outros modelos. De acordo com outro entrevistado, a tabela de medidas foi feita em cima das medidas da 
proprietária: "ela veste $\mathrm{M}$, mas ela quer vestir $\mathrm{P}$, então nosso $\mathrm{P}$ é um pouco maior e em cima disso foi feita as graduações".

Segundo o entrevistado E1, a empresa está investindo na criação de uma tabela de medida após 6 anos de existência. A empresa pediu auxílio a uma pessoa que possui experiência de 20 anos com modelagem e que também possui empresa de confecção de vestuário.

O entrevistado E9 percebeu através da análise de fichas técnicas que a tabela de medidas disponibilizadas pelos clientes vem sofrendo alterações no comprimento e largura.

\subsection{Etapa de confecção do protótipo e realização de testes}

Com a peça protótipo confeccionada é ideal que uma pessoa cujas medidas correspondam com a tabela de medidas utilizada no desenvolvimento da modelagem, realize a prova na qual serão feitos os ajustes necessários (TREPTOW, 2013; RENFREW E RENFREW, 2010). Para uma melhor avaliação do ajustamento de uma peça, é ideal que seres humanos experimentem, já que manequins possuem limitações, são duros, não se movem ou dobram (ARAÚJO, 1996).

Sanches (2014, p.294) ressalva a importância da "experimentação de quesitos de conforto, manutenção, vestibilidade e segurança, para evitar a insatisfação do usuário, considerando que o bem-estar psicológico está intrinsecamente ligado à boa adaptação do vestuário ao corpo".

Nas entrevistas realizadas, 12 profissionais afirmaram provar as peças protótipos em pessoas, 3 em manequins e 1 não realiza provas. Entre os entrevistados que realizam provas com pessoas apenas um deles destacou a importância de provar em um modelo que tenha o corpo de acordo com as medidas correspondeste da tabela utilizada pela empresa. Para os demais, a prova é feita em pessoas aleatórias, como funcionários da empresa, parentes, vizinhos e amigos. O entrevistado E12 afirma que não realizam provas e acredita que esta foi feita somente quando a base foi desenvolvida.

$\mathrm{Na}$ empresa de E9, na linha plus size é realizada provas de protótipos: "nas três costureiras mais gordinhas, sendo que uma é mais alta e a outra é mais baixinha, aí chega ao meio termo entre elas". Na empresa de E15, duas funcionárias provavam, 
sendo uma tamanho 38 e outro 40, ficando bom nelas estava liberado para produção. Para E6, a linha infantil é provada apenas na hora de fazer o catálogo, pois exige a contratação dos modelos.

O entrevistado E11 comenta sobre o problema de falta de padrão na escolha dos modelos para prova, os quais eram escolhidos conforme a vontade da proprietária. A empresa está em busca de uma modelo no padrão do tamanho 38, mas em uma semana podia ser uma funcionária da produção, na outra podia ser uma sobrinha. E11 afirma que muitas vezes provou as peças, porém como tinha busto pequeno em relação ao quadril, as peças ficavam grandes na parte de cima e apertadas na parte de baixo dificultando o teste e os ajuste.

\section{Considerações Finais}

O objetivo deste artigo foi identificar o usuário nas etapas de criação, modelagem e prototipagem do vestuário. Para isso, foram entrevistados 15 profissionais da área, entre eles estilistas, modelistas e auxiliares, os quais foram questionados sobre etapas do processo de desenvolvimento de produto do vestuário e após explicaram mais detalhadamente sobre as etapas de criação, modelagem e prototipagem.

Sobre a consideração do usuário na etapa da criação, percebeu-se a dificuldade em que os profissionais possuem em explicar o público-alvo para os quais desenvolvem os produtos de vestuário. Nenhum entrevistado comentou o estilo de vida do público-alvo, ficando principalmente nas definições básicas de faixa-etária e classe social, as quais não são suficientes para desenvolver produtos focados no usuário.

Essa falta de visualização do usuário final também pode vir em decorrência do desejo das empresas em querer atingir um público muito abrangente, as quais podem estar perdendo a oportunidade de oferecer produtos diferenciados e atender melhor seus clientes.

A respeito da consideração do usuário na etapa da modelagem mais da metade dos entrevistados não sabem explicar sobre a tabela de medidas utilizadas no desenvolvimento das peças do vestuário. Aproximadamente $40 \%$ dos entrevistados destacaram a realização de ajustes, adaptações, reformulações, pesquisas na ABNT, análises de peças de marcas concorrentes para melhoria na tabela de medidas utilizada. Percebeu-se que os entrevistados sabem da importância de uma tabela de medidas 
correspondente com as medidas do público-alvo, porém muitos não sabem muito bem como ajustar, sendo essa alteração de forma empírica.

$\mathrm{Na}$ etapa da prototipagem, em $80 \%$ das empresas, são realizadas provas com seres humanos, porém a representação do usuário final nos modelos escolhidos para realizar a prova não condiz com a realidade. Em muitas vezes, a prova de protótipo é feita em uma pessoa escolhida de forma aleatória, como por exemplo, um funcionário da empresa, parentes, amigos ou vizinhos. Analisando essa prática é possível que peças sejam ajustadas em corpos não correspondentes com o usuário e isto acabe gerando futuras insatisfações nos mesmos no momento da compra.

Recomenda-se para um próximo estudo a divisão dos profissionais selecionados para entrevistas, pela diferença das atividades entre os profissionais que trabalham para marcas próprias e dos profissionais que desenvolvem produtos para os magazines. Empresas que produzem para os magazines recebem pesquisas ou briefing prontos para orientar o desenvolvimento dos produtos. Nestes casos, a tabela de medidas também é fornecida pelo magazine e os profissionais acabam trabalhando em cima dos materiais fornecidos sem o dever de realizar pesquisas sobre o usuário.

\section{Artigo recebido em Outubro de 2016. Aprovado em Novembro de 2016 DOI:http://dx.doi.org/105965/1982615x10192016201}

\section{Referências}

ARAÚJO, Mario de. Tecnologia do Vestuário. Lisboa. Fundação Calouste Gulbenkian. Gulbenkian, Edição/reimpressão: 1996.

BOUERI, José Jorge. Sob medida: antropometria, projeto e modelagem. In: PIRES, Dorotéia Baduy (Org.). Design de moda: olhares diversos. Barueri: Estação das Letras e Cores, 2014.

GUERRA, Isabel Carvalho. Pesquisa qualitativa e análise de conteúdo: sentidos e formas de uso. São João do Estoril: Princípia, 2012.

MATHARU, Gurmit. O que é design de moda?. Porto Alegre: Bookman, 2011.

MONTEMEZZO, Maria Celeste de Fátima Sanches. Diretrizes metodológicas para o 
projeto de produtos de moda no âmbito acadêmico. 2003. 98 f. Dissertação (Mestrado) - Curso de Desenho Industrial, Universidade Estadual Paulista Faculdade de Arquitetura, Artes e Comunicação, Bauru, 2003. Cap. 9.

RECH, Sandra Regina. Moda: por um fio de qualidade - Florianópolis: Udesc, 2002.

RENFREW, Elinor; RENFREW, Colin. Desenvolvendo uma coleção. Porto Alegre: Bookman, 2010.

ROSA, Lucas da. Vestuário industrializado: uso da ergonomia nas fases de gerência de produto, criação, modelagem e prototipagem. 2011: 175 p.: Tese (doutorado) Pontifícia Universidade Católica do Rio de Janeiro, Programa de Pós-graduação em Design do Departamento de Artes e Design, Rio de Janeiro, 2011.

SANCHES, Maria Celeste de Fátima. Projetando moda: diretrizes para a concepção de produtos. In: PIRES, Dorotéia Baduy (Org.). Design de moda: olhares diversos. Barueri: Estação das Letras e Cores, 2014.

SILVEIRA, Icléia. Um modelo para capacitação dos instrutores do sistema CAD para vestuário e dos modelistas, com foco na gestão do conhecimento. 2011. 305 f. Tese (Doutorado) - Curso de Design, Departamento de Artes e Design, Pontifícia Universidade Católica do Rio de Janeiro, Rio de Janeiro, 2011. Cap. 9.

SORGER, Richard; UDALE, Jenny. Fundamentos de Design de Moda - Porto Alegre: Bookman, 2009.

TREPTOW, Doris. Inventando moda: planejamento de coleção. 5. ed. São Paulo: Edição da Autora, 2013.

VICENTINI, Cláudia Regina Garcia. Ferramentas e metodologia de projeto aplicados na criação de produtos para a indústria têxtil-confecção. 2010. $157 \mathrm{f}$. Tese (Doutorado) Curso de Engenharia Mecânica, Projeto Mecânico, Universidade Estadual de Campinas Faculdade de Engenharia Mecânica, Campinas, 2010. Cap. 7. 